8. Davis. P. B. and Sant'Agnese. P. A.: A review. Cystic fibrosis at forty-quo vadis? Pediatr. Res.. 14:83 (1980).

9. Editorial: Cystic fibrosis. Diagnostic hopes. Nature 290: 536 (1981).

10. Errede, B., Kamen. M. D., and Hatefi, Y.: Preparation and properties of complex IV (ferrocytochrome c: oxygen oxidoreductase EC 1.9.3.1). Methods Enzymol. 53: 40 (1978).

11. Feigal, R. J. and Shapiro. B. L.: Mitochondrial calcium uptake and oxygen consumption in cystic fibrosis. Nature. 278: 276 (1979).

12. Fiskum. G. and Lehninger, A. L.: Mitochondrial regulation of intracellula calcium. In: W. Y. Cheung: Calcium and Cell Function. Vol. II. pp. 39-80 (Academic Press. New York. 1982)

13. Galante, Y. M. and Hatefi. Y.: Resolution of complex I and isolation of NADH dehydrogenase and an iron-sulfur protein. Methods Enzymol., 53: 15 (1978).

14. Hackenbrock. C. R.: Review. Lateral diffusion and electron transfer in the mitochondrial inner membrane. Trends Biochem. Sci., 6: 151 (1981).

15. Hatefi, Y. and Stignall, D. L.: Preparation and properties of NADH:cytochrome c oxidoreductase (complex I-III). Methods Enzymol., 53: 5 (1978).

16. Horton, C. R.. Cole, W. Q.. and Bader, H.: Depressed (Ca $\left.{ }^{++}\right)$-transport ATPase in cystic fibrosis erythrocytes. Biochem. Biophys. Res. Commun., 40:505 (1970).

17. von Jagow, G.: personal communication.

18. Katz. S.: Calcium and sodium transport processes in patients with cystic fibrosis. I. A specific decrease in $\mathrm{Mg}^{2+}$-dependent $\mathrm{Ca}^{2+}$-adenosine triphosphatase activity in erythrocyte membranes from cystic fibrosis patients. Pediatr. Res., 12: 1033 (1978).

19. King. T. E.: Preparations of succinate-cytochrome $c$ reductase and the cytochrome $b-c_{1}$ particle, and reconstruction of succinate-cytochrome $c$ reductase. Methods Enzymol.. 10: 216 (1967)

20. King. T. E.: The Keilin-Hartree heart muscle preparation. Methods Enzymol. 10: 202 (1967).

21. Lowry. O. H. Rosebrough. V. J. Farr. A. L., and Randall, R. J.: Protein measurement with the folin phenol reagent. J. Biol. Chem. 193:265 (1951).

22. Nicholls, D. G.: The regulation of extramitochondrial free calcium ion concentration by rat liver mitochondria. Biochem. J.. 176: 463 (1978).

23. Rasmussen, H. and Goddman. B. P.: Relationship between calcium and cyclic nucleotides in cell activation. Physiol. Rev.. 57: 422 (1977).

24. Reed. K. C. and Bygrave, F. L.: Methodology for in vitro studies of $\mathrm{Ca}^{2+}$ transport. Anal. Biochem. 67:44 (1976).

25. von Ruecker, A., Bauer, R., Shin, Y. S.. Endres, W.. Bertele, R., and Harms,
K.: Cystic fibrosis-a mitochondrial defect? Eur. J. Pediatr., 138: 94 (1982). 26. Schncider. H.. Lemasters. J. J., and Hackenbrock. C. R.: Lateral diffusion of ubiquinone during electron transfer in phospholipid- and ubiquinone-enriched mitochondrial membranes. J. Biol. Chem., 257: 10789 (1982).

27. Schneider, H. and Hackenbrock. C. R.: The significance of protein and lipid mobility for catalytic activity in the mitochondrial membranc. In: A. N. Martinosi: Membranes and Transport. Vol. 1. pp. 431-435 (Plenum Press. New York. 1982)

28. Shapiro. B. L.. Feigal, R. J., and Lam, L. F-H.: Intracellular calcium and cystic fibrosis. In: J. M. Sturgess: Perspectives in Cystic Fibrosis. Proc. 8th Int. Congr. CF. Toronto. Canada. pp. 15-28 (Imperial Press. 1980).

29. Shapiro, B. L., and Lam, L. F-H.: Calcium and age in fibroblasts from control subjects and patients with cystic fibrosis. Science 216:417 (1982)

30. Shapiro, B. L.. Lam, L. F.H., and Feigal. R. J.: Mitochondrial NADH dehydrogenase in cystic fibrosis: enzyme kinetics in cultured fibroblasts. Am. J. Hum. Genet. 34: 846 (1982)

31. Shwachmann. H. and Kulczycki, L. L.: Longterm study of one hundred live patients with cystic fibrosis: studies made over a five- to fourteen-year period Am. J. Dis. Child. 96: 6 (1958).

32. Sorscher. E. J. and Breslow, J. L. Cystic fibrosis: a disorder of calciumstimulated secretion and transepithelial sodium transport? Lancet. 1.368 (1982).

33. Sturgess. J. M.: Perspectives in cystic fibrosis. Proc. 8th Int. Congr. CF. Toronto Canada (Imperial Press. Mississauga. Canada. 1980).

34. Talamo R C Rosenstein. B J and Berninger. R W : Cystic fibrosis. In: J B. Stanbury; J. B. Wyngaarden: D. S. Fredrickson: J. L. Goldstein and M. S. Brown: The Metabolic Basis of Inherited Disease. pp. 1889-1917 (MCGraw-Hill. New York. 1983)

35. United States. Vilal statistics. 1981

36. We are indebted to G. von Jagow (Institut für Physiologische Chemie, University of Munich. FRG) and B. L. Shapiro (Department of Oral Biology, University of Minnesota. USA) for valuable help and discussions.

37. Requests for reprints should be addressed to: Dr. Axel von Ruecker. Universitäts Kinderklinik. Lindwurmstr. 4. D-8000) Munich 2. West Germany.

38. This work was supported by a grant from the Deutsche Forschungsgemeinschaft.

39. Received for publication April 18.1983

40. Accepted for publication September 21, 1983.

\title{
Pre- and Postnatal Development of Granulocytic Stem Cells in the Rat
}

\author{
ROBERT D. CHRISTENSEN ${ }^{(22)}$ AND GERALD ROTHSTEIN \\ Departments of Pediatrics and Internal Medicine, University of Utah School of Medicine, and the Primary \\ Children's Medical Center, Salt Lake City, Utah, USA
}

\section{Summary}

Bacterial sepsis is a relatively common problem in the neonatal period, particularly among prematurely delivered infants. The newborn rat has been widely used as a model for sepsis neonatorum, and in that model incomplete development of the neutrophil system has been postulated to be an important factor predisposing neonates to death from bacterial infection. In this study, that hypothesis was further tested by assessing neutrophil development in rats of various pre- and postnatal ages. Using standard soft agar colony techniques for detecting granulocyte-macrophage progenitor cells [CFU(c)], the number of $\mathrm{CFU}(\mathrm{c}) / \mathrm{g}$ of body weight was seen to increase from $0.5+0.1 \times 10^{3}$ at $19-20$ days gestation to $10.5 \pm 0.2 \times 10^{3}$ at 4 weeks. The anatomic location of $\mathrm{CFU}(\mathrm{c})$ changed from totally hepatic at $\mathbf{1 6}$ days gestation to almost totally myeloid at 4 weeks. Lastly, the proportion of mature, stored neutrophils/CFU(c) decreased from $2440 \pm 40$ at 19-20 days gestation to $430 \pm 75$ at 4 weeks.

\section{Abbreviations}

CFU(c), colony-forming unit in culture PMN, polymorphonuclear leukocyte M5A, McCoy's 5A medium

Very early in gestation, it is unlikely that a fetus, existing in a sterile environment, requires the antimicrobial neutrophil system. Indeed, although red blood cells circulate in the human fetus before the 5th week of gestation (19), mature neutrophils generally do not appear until after the 12 th to 14 th week (13) and then exist only in very minute concentration until after birth (16). Because of this late appearance of neutrophils during human gestation, we postulated that infants born prematurely might possess an incompletely developed neutrophil system and that this deficiency might, in part, be responsible for the high incidence of bacterial infection in this group of patients (18). In 
the present study, we examined a critical segment of neutrophil development in rats of various pre- and postnatal ages by quantifying the granulocyte-macrophage progenitor cells (11) [CFU(c)]. We determined: 1) the number of $\mathrm{CFU}(\mathrm{c}) / \mathrm{g}$ of body weight, 2) the anatomic location of the CFU(c); and 3) the ratio of mature stored neutrophils to CFU(c).

Experimental animals. Simonson albino Sprague-Dawley rats (Simonson Laboratories, Gilroy, CA) at various ages were tested. Rats at 10,16, and 19-20 days gestation were delivered by hysterotomy from animals with timed gestations. Other rats were studied either late on the first day of life $(12-14 \mathrm{~h})$ or at 1,2 , or 4 weeks of age.

CFU(c) quantification. CFU(c) within the liver, spleen, bone marrow, and blood were quantified in animals anesthetized with methoxyfluorane (Abbott Laboratories, Chicago, IL). The liver and spleen were removed and, using sterile technique, separately subjected to sieving in M5A medium (Grand Island Biological, Grand Island, NY). The absolute number of nucleated cells per organ was calculated using the volume of cell suspension and concentration of nucleated cells measured by electronic cell counting (Coulter Electronics, Hialeah, FL). The cellularity of femoral marrow was determined by flushing the contents of both femurs into M5A, and counting the cells electronically. The cellularity of the entire skeletal marrow was calculated by utilizing the femoral marrow/total skeletal marrow relationship at various ages previously reported (8). The nucleated cell content of blood was determined by electronic counting and assuming a total blood volume of $0.01 \mathrm{ml} / \mathrm{g}$ of body weight (17). Sterile suspensions of cells from the spleen, liver, femoral marrow, and blood were added to $1 \mathrm{ml} \mathrm{M} 5 \mathrm{~A}$ with $15 \%$ fetal calf serum, $3 \%$ agar (Difco Laboratories, Detroit, MI), 200,000 units/liter penicillin, $200 \mathrm{mg} /$ liter streptomycin, and $3 \%$ postendotoxin serum, as a source of colony-stimulating factor (15). As in our previous studies $(3,4)$, this concentration of postendotoxin serum $(3 \%)$ promoted maximal colony growth. The postendotoxin serum was obtained $3 \mathrm{~h}$ after the intravenous injection of $10 \mu \mathrm{g} \mathrm{Sal}$ monella typhosa endotoxin (Difco)/g of body weight in adult rats and was frozen at $-70^{\circ} \mathrm{C}$ until use. Mixtures which contained $25,000,50,000$, and 100,000 cells $/ \mathrm{ml}$ were plated with $6-10$ replicates in $10 \times 35 \mathrm{~mm}$ plastic dishes (Becton Dickinson and $\mathrm{Co}$, Oxnard, $\mathrm{CA}$ ) and incubated at $37^{\circ} \mathrm{C}$ in a $7 \% \mathrm{CO}_{2}$, high humidity atmosphere (Wedco, Inc., Silver Spring, MD) for 7 days, after which colonies of greater than 50 cells were counted using a stereomicroscope. In this way, the absolute number of $\mathrm{CFU}(\mathrm{c})$ within each site was determined and by summing the absolute number of CFU(c) from the liver, spleen, skeletal marrow, and blood, the quantity of $\mathrm{CFU}(\mathrm{c})$ within the entire animal was calculated. In premature and term newborn animals, the liver, spleen, and marrow from two individuals were combined. Therefore, 20 animals contributed cells for 10 experiments, each with $6-10$ replicates. The liver, spleen, and marrow of 1-, 2-, and 4-week-old animals contained a sufficient quantity of cells to make combining organs from two animals unnecessary. However, in order to obtain a sufficient quantity of circulating nucleated cells, the blood samples from 2-10 animals were combined for each blood CFU(c) data point. Again, 10 such points, each with 6-10 replicates were obtained.

Quantification of mature storage neutrophils. The number of storage neutrophils (PMNs, band neutrophils, and metamyelocytes) within the bone marrow, liver, and spleen of animals at various ages was determined as previously described (8). Briefly, 1000-2000 cell differential counts were performed on Wrightstained coverslip smears made from cell suspensions of femoral marrow, liver, and spleen. The absolute number of mature storage neutrophils within these organs was calculated by multiplying the per cent PMNs, bands, and metamyelocytes by the absolute nucleated cells counts.

\section{RESULTS}

The number of CFU(c)/g of body weight in rats of various ages is shown in Figure 1. At 19-20 days gestation (term $=21$ days), animals had $0.5 \pm 0.1 \times 10^{3} \mathrm{CFU}(\mathrm{c}) / \mathrm{g}$ of body weight (mean \pm SEM), (mean CFUc/animal, 2580; mean weight, 5.1 g). One day following birth, CFU(c) had increased to $1.6 \pm 0.1$ $\times 10^{3} / \mathrm{g}$ (mean CFUc/animal, 9840; mean weight, $6.0 \mathrm{~g}$ ) and by 1 week there were $2.0 \pm 0.1 \times 10^{3} / \mathrm{g}$ (mean CFUc/animal, 20.4 $\times 10^{3}$; mean weight, $10.2 \mathrm{~g}$ ). At 2 weeks of age, stem cell number had increased further to $2.8 \pm 0.2 \times 10^{3}$ (mean CFUc/animal, $68 \times 10^{3}$; mean weight, $24.3 \mathrm{~g}$ ) and 4-week-old rats had $10.5 \pm$ $0.2 \times 10^{3} \mathrm{CFU}(\mathrm{c}) / \mathrm{g}$ (mean CFUc/animal, $855 \times 10^{3}$; mean weight $81.4 \mathrm{~g}$ ). At 10 days gestation, no CFU(c) could be detected. Thus, over the period from 1-2 days before birth to 4 weeks of age, the number of granulocyte-macrophage progenitors/g of body weight increased by over 20 -fold.

In Figure 2, the anatomic location of the CFU(c) at these various ages is displayed. Prior to the 17 th day of gestation, we could not macroscopically identify the spleen [the rat spleen is formed at 15 days gestation (2)] nor could we obtain peripheral blood; therefore, only hepatic and myeloid CFU(c) were measured on day 16 and all CFU(c) were seen to be located within the liver. By 19-20 days gestation, the liver was the predominant site of CFU(c), with smaller numbers in the spleen and marrow. Thereafter, the site of CFU(c) location gradually shifted to the bone marrow and by 4 weeks of age and the marrow contained essentially all of the CFU(c). The blood never contained more than $1 \%$ of total body CFU(c) and consequently is not shown in the figure.

The ratio of postmitotic storage neutrophils (PMN, band neutrophils, and metamyelocytes) within the bone marrow, liver, and spleen, to the number of CFU(c) was also determined and is shown in Figure 3. Animals 1-2 days before birth were seen to have a significantly greater ratio of stored neutrophils to stem

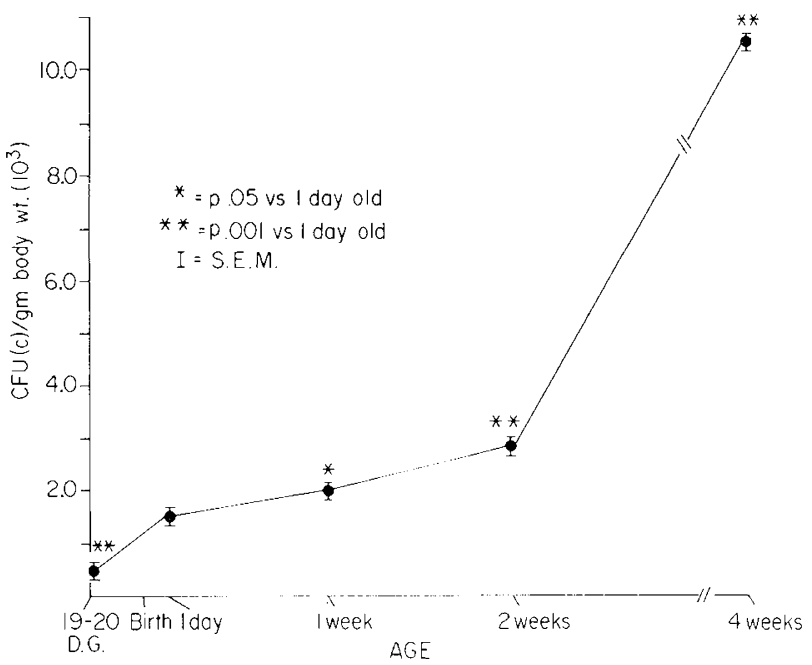

Fig. 1. The number of $\mathrm{CFU}(\mathrm{c}) / \mathrm{g}$ of body weight measured in groups of 10 or more rats at various pre- and postnatal ages: 19-20 days gestation (DG), 1 day after birth, 1 week, 2 weeks, and 4 weeks of age.

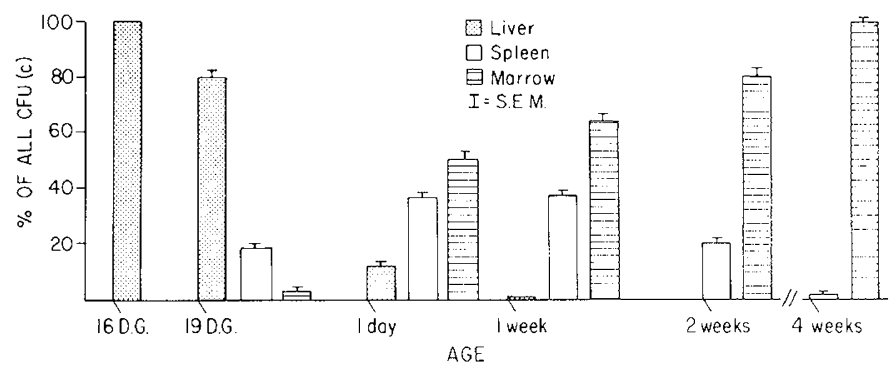

Fig. 2. The anatomic location of $\mathrm{CFU}(\mathrm{c})$ in groups of 10 or more rats of various pre- and postnatal ages: 16 days gestation (D.G.), 19 days gestation, 1 day, 1 weeks, 2 weeks, and 4 weeks old. 


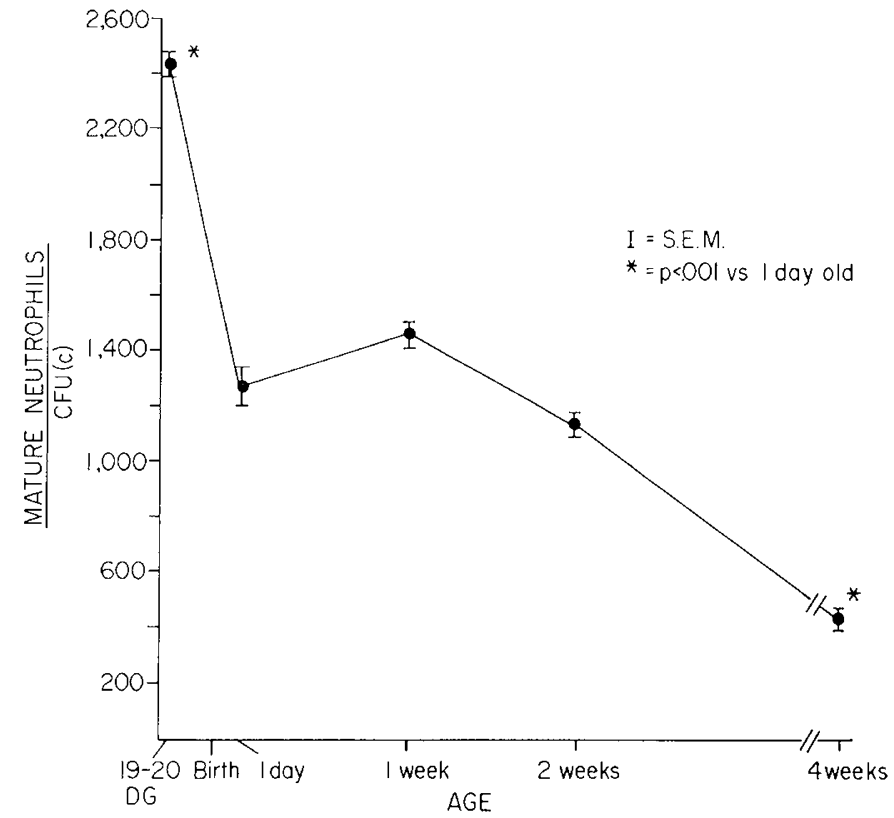

Fig. 3. The ratio of mature, stored neutrophils (PMNs + band neutrophils + metamyelocytes) to CFU(c) in rats of various pre- and postnatal ages: 19-20 days gestation (D.G.), 1 day, 1 weeks, 2 weeks, and 4 weeks of age.

cells, [2440 \pm 40 stored neutrophils/CFU(c), than animals at 4 weeks of age ( $430 \pm 75$ stored neutrophils/CFU(c)].

\section{DISCUSSION}

Analogous to the pulmonary system, the neutrophil system develops late in gestation, yet must be functionally operational by the time of birth if extrauterine existence is to be successful. The extent to which a prematurely born individual is compromised because of an incompletely developed neutrophil system, and the degree of neutrophil development at the time of normal term birth have been the subjects of several reports from this and other laboratories. In those studies, it has been observed that: 1 ) newborn animals are much more susceptible to death from bacterial infection than are older animals $(5,20) ; 2)$ during lethal bacterial sepsis, profound neutropenia and marked depletion of storage neutrophils occurs $(5-7,20) ; 3)$ the quantity of stored, mature neutrophils is much smaller in prematurely born animals $\left(1 \times 10^{6} / \mathrm{g}\right.$ of body weight) than in those at term $\left(2 \times 10^{6} / \mathrm{g}\right)$ or at 1,2 , or 4 weeks of life $\left(5 \times 10^{6} / \mathrm{g}\right.$ at 4 weeks), $\left.{ }^{8} 4\right)$ during bacterial infection in adult rats, CFU(c) rapidly increase in number and in proliferative rate; however, neither the CFU(c) number nor the proliferative rate increases in infected newborn rats $(3,4)$. The explanation for this latter finding appears to be that the CFU(c) cell cycle in fetal and neonatal rats is already maximally shortened in the noninfected state; therefore, an additional increase in proliferative activity is not possible (4).

In the present studies, we extend these observations by quantifying: 1) CFU(c)/g of body weight; 2) the anatomic location of $\mathrm{CFU}(\mathrm{c})$; and 3) the ratio of mature, stored neutrophils/CFU(c) in developing rats of various pre- and postnatal ages. Metcalf and Moore (11) observed that the first CFU(c) to appear in fetal mouse liver do so at $10-11$ days gestation (term $=19$ days). We could not demonstrate CFU(c) at 10 days gestation in the fetal rat liver (term $=21$ days), but at 16 days gestation, $0.5 \pm 0.1 \times$ $10^{3} \mathrm{CFU}(\mathrm{c}) / \mathrm{g}$ of body weight were seen. Thereafter, the quantity of $\mathrm{CFU}(\mathrm{c}) / \mathrm{g}$ increased markedly with increasing age, reaching $10.5 \pm 0.2 \times 10^{3} / \mathrm{g}$ at 4 weeks of age, a value comparable to 8.5 $\times 10^{3} \mathrm{CFU}(\mathrm{c}) / \mathrm{g}$ reported by Lipshitz and Udupa (10) in adult mice and $14 \times 10^{3} / \mathrm{g}$ in adult humans.

We observed that the anatomic location of CFU(c) in the developing rat basically parallels the pattern of maturation de- scribed by Metcalf and Moore (11) in fetal rnice, with the liver containing the first visceral CFU(c), the spleen assuming a myelopoietic role only a few days before term, and skeletal marrow containing very few CFU(c) until following birth. However, one qualitative difference was seen: in the mouse, the spleen continues as a significant source of CFU(c) in adult life (11), yet in the developing rat, only very small numbers of splenic CFU(c) remain after 3 weeks of age. One can see that the change from extramyeloid to myeloid production of neutrophilic stem cells is not complete by the time of term birth, and in fact, myeloid neutrophil production has not even commenced in rats delivered only a few days prematurely. Whether neutrophils produced in nonmyeloid tissue differ from those produced within the marrow, and whether this difference confers any disadvantage or advantage to the host remains to be determined. Similarly, the mechanisms which induce this change in the site of neutrophil production during gestation and postnatal life await description.

Finally, we measured the ratio of mature, stored neutrophils to CFU(c) at various ages and detected marked differences. At 19-20 days gestation, the fetal rat possesses $2440 \pm 40 \mathrm{PMN}$, band neutrophils, and metamyelocytes within the liver, spleen, and skeletal marrow for every CFU(c). This proportion falls after birth, and continues to fall to $430 \pm 75$ mature neutrophils/ CFU(c) at 4 weeks of age. We speculate that this change may be due to at least two factors. First, the fetal rat, while producing neutrophils, may not yet be utilizing them, because it exists in a sterile environment. Rather, fetal neutrophil production may largely be for the purpose of accumulating a neutrophil reserve in anticipation of the requirement for neutrophils following birth. It can be speculated that a fetus, with a small mass of CFU(c)/g, a very rapid $\mathrm{CFU}(\mathrm{c})$ proliferative rate (4), and yet decreased neutrophil utilization, would likely maintain a relatively large proportion of stored mature neutrophils to CFU(c), as we have observed. This is also consistent with observation of Miller et al. (12) that the circulating neutrophil concentration in fetal sheep is very low, frequently with no measurable circulating neutrophils at all until birth, when neutrophilia occurs. Secondly, perhaps the proliferative neutrophils of a fetus and neonate undergo one or two more cell divisions than do neutrophils of older animals. This is supported by our observation that in newborn rats the concentration of myeloperoxidase [a granulocyte enzyme produced only at the promyelocyte stage (1)] is only $27 \%$ of that found in the neutrophils of older animals (14). One possible explanation for this finding is that additional cell division(s) in the fetal and neonatal myelocyte divide a fixed quantity of myeloperoxidase between larger numbers of mature neutrophil progeny. Further support for this idea is derived from the work of Grouls and Helpap (9) who injected newborn rats with tritiated thymidine and based on labeling index in the marrow concluded tha an additional cell division likely occurs at the neonate's myelocyte stage.

We conclude that the neutrophil system is not fully developed in either prematurely delivered, or term rats. One to two days before birth, the number of CFU(c)/g of body weight is very small, but growing rapidly, the site at which neutrophils are produced is changing daily, and the relationship of the quantity of mature neutrophils/CFU(c) falls significantly during this fetal to adult transition. In prematurely born subjects, the limitations on neutrophil supply imposed by these and the other previously discussed factors may in part be responsible for the rapid depletion of the neutrophil reserves and the high mortality rate during bacterial infection.

\section{REFERENCES AND NOTES}

1. Bainton DF 1971 The development of neutrophilic PMN leukocytes in human bone marrow: origin and content of azurophilic and specific granules. J Exp Med 134:907

2. Borghese E 1959 Acta Anat $36: 185$

3. Christensen RD, Macfarlane JL, Taylor NL, Hill HR, Rothstein G 1982 Blood and marrow neutrophils during experimental group B streptococcal infection: quantification of the stem cell, proliferative, storage and circulating pools. Pediatr Res 16:549 
4. Christensen RD. Hill HR. Rothstein 1983 Granulocytic stem cell CFU(c) proliferation in experimental group B streptococcal sepsis. Pediatr Res 17:278

5. Christensen RD. Shigeoka AO. Hill HR, Rothstein G 1980 Circulating and storage neutrophil changes in experimental type II group B streptococcal sepsis. Pediatr Res 14:806

6. Christensen RD. Bradley PP, Rothstein G 1981 The leukocyte left shift in clinical and experimental group B streptococcal sepsis. J Pediatr 98:101

7. Christensen RD, Bradley PP. Priebat DA, Anstall HB, Rothstein G 1982 Granulocyte transfusion in septic canine neonates. Pediatr Res 16:57

8. Erdman SH. Christensen RD. Bradley PP. Rothstein G 1982 The supply and release of storage neutrophils: a developmental study. Biol Neonat 41:132

9. Grouls V. Helpap B 1980 The granulocytopoiesis in the spleen of newborn rats. Res Exp Med 177:237

10. Lipschitz DA, Udupa KB 1981 The quantitation of the granulocytic/macrophage committed progenitor cell CFU(c) in man and the mouse. Exp Haematol 9:723

11. Metcalf D, Moore MAS 197 I Haemopoietic Cells. Amsterdam, North-Holland Publishing Co

12. Miller ME, Raghunathan R. Siegler L 1981 Ontogeny of chemotaxis in ovine polymorphonuclear leukocytes. Clin Res 29:123(A)

13. Playfair JHL. Wolfendale MR, Kay HEM 1963 The leucocytes of peripheral blood in the human foetus. Br J Haematol 9:336
14. Rothstein $G$, Christensen RD Unpublished observations

15. Till JE. McCulloch EA 1980 Hemopoietic stem cell differentiation. Biochim Biophys Acta 605:431

16. Thomas DB. Yoffey JM Human foetal haematopoiesis. I. The cellular composition of foetal blood. Br J Haematol 8:290

17. Usher R. Lind J 1965 Blood volume of the newborn premature infant. Acta Paediatr Scan 54:419

18. Wientzen RL, McCracken GH, Jr 1977 Pathogenesis and management of neonatal sepsis and meningitis. In: Current Problems in Pediatrics, vol 8, p 1

19. Wintrobe MM, Shumacker HB, Jr 1935 Comparison of hematopoiesis in the fetus and during recovery from pernicious anemia. J Clin Invest 14:837

20. Zeligs BJ, Armstrong CD, Walser JB, Bellanti JA 1982 Age-dependent susceptibility of neonatal rats to group B streptococcal type III infection: correlation of severity of infection and response of myeloid pools. Infect Immun 37:255

21. Supported by United States Public Health Service Grant HD-14419 and by a grant from the Thrasher Research Fund. Presented in part at the Society for Pediatric Research, Washington, D. C. May, 1983.

22. Requests for reprints should be addressed to: Robert D. Christensen MD. Division of Hematology, University of Utah School of Medicine, 50 North Medical Drive, Salt Lake City, Utah 84132

23. Received for publication November 16, 1983

\title{
Increased Regional Myocardial Blood Flows and Oxygen Deliveries during Hypoxemia in Lambs
}

\author{
DAVID J. FISHER ${ }^{(4)}$ \\ With the technical assistance of Elizabeth Ott \\ Department of Pediatrics, Medical School, The University of Texas Health Science Center at Houston, \\ Houston, Texas USA
}

\begin{abstract}
Summary
Newborn humans may develop myocardial dysfunction in conjunction with severe birth asphyxia. Subendocardial or papillary muscle ischemia appears to be the basis for the myocardial dysfunction, yet patent coronary arteries have been demonstrated in the nonsurvivors. The asphyxiated newborns also have experienced hypoxemia, which has been suggested as the cause of myocardial ischemia. This study was designed to determine the relationship between reduced aortic blood oxygen content and blood flow as well as oxygen delivery within different regions of the heart. Three days after surgery, we measured blood flow and oxygen delivery to the free walls and papillary muscles of the right and left ventricles, the ventricular septum, and the atria in 10 lambs, during 20-min periods in 8-10\% and 5-6\% environmental oxygen concentrations. In each region of myocardium, blood flow increased linearly as the aortic blood oxygen content decreased. The slopes of the regression lines were similar for each region of ventricular myocardium. Atrial myocardial blood flow also increased as a linear function of the reductions in aortic blood oxygen content, but at a slower rate than in the ventricular regions. Hypoxemia was associated with increased oxygen delivery in each region of myocardium, but the two variables were not related in a linear or quadratic fashion. The results demonstrate that isolated hypoxemia is associated with increased blood flow and oxygen delivery in the free walls and papillary muscles of the right and left ventricles, the ventricular septum, and the atria.
\end{abstract}

Several reports have demonstrated that newborn humans may develop regional or global myocardial dysfunction in conjunction with severe birth asphyxia $(6,7,33)$. Subendocardial and/ or papillary muscle ischemia appears to be the basis for the myocardial dysfunction $(4,12,30,33)$. While coronary stenoses are present in most adults who develop myocardial ischemia, there has been no evidence of coronary stenoses in asphyxiated newborns who have expired after developing severe myocardial dysfunction $(4,12,30,33)$. Consequently, the factor(s) that produce myocardial ischemia during birth asphyxia remain to be determined (33).

Several investigators have suggested that the myocardial ischemia of birth asphyxia may be the result of the simultaneous occurrence of hypoxemia, with or without additional stresses such as hypoglycemia $(4,21,30)$. In contrast, our recent work in unanesthetized fetal and newborn lambs has demonstrated that blood flow to the left ventricular free wall increased during hypoxemia $(13,14)$. Since right and/or left ventricular ischemia and dysfunction may occur in asphyxiated human newborns, the present investigation was designed to determine the relationship between hypoxemia and blood flow as well as oxygen delivery within the papillary muscles and free walls of the right and left ventricles, the ventricular septum, and the atria.

\section{MATERIALS AND METHODS}

Surgical technique. Using techniques previously described, we operated on 10 Western newborn lambs 1 to 11 days $(5 \pm 2$, 